\title{
Diagnóstico da estrutura urbana de ocupação desordenada na zona leste da cidade de Manaus, Âmazonas.
}

\author{
Diagnosis of the urban structure of disordered occupation in the \\ east of the city of Manaus, Amazonas.
}

\author{
Alan dos Santos Ferreira ${ }^{* 1}$, Lizit Alencar da Costa ${ }^{2}$ \\ ${ }^{1}$ CEULM/ULBRA \\ ${ }^{2} \mathrm{UFAM}$
}

\begin{abstract}
Resumo
Com o processo de expansão urbana, incitado pelo crescimento populacional e desenvolvimento das atividades produtivas e comerciais, entre outros fatores, trouxeram diversos problemas às cidades e às suas populações. Como consequência de um planejamento inadequado de ordenamento territorial, essa expansão produziu um ambiente urbano degradado, com grande influência sobre a qualidade de vida da população, tendo como principais condicionantes dessa ocupação desordenada determinantes demográficos e socioeconômicos. Neste sentido, estudamos a estrutura urbana de uma área de ocupação desordenada na Zona Leste da Cidade de Manaus. As áreas selecionadas foram as comunidades Jorge Teixeira $3^{a}$ etapa, Bairro Novo, Arthur Virgílio Filho e João Paulo, integrantes da Unidade de Estrutura Urbana UES (bairro) Jorge Teixeira, conforme Plano Diretor Ambiental Urbano de 2008 da cidade de Manaus. Para a análise e execução da pesquisa, para o gerenciamento e tabulação dos dados para manipulação das informações cadastrais e dos atributos espaciais utilizou-se a padronização dos arquivosshapefile (.shp), os softwares utilizados foram o ArcGis 9.3 e Spring 4.1, ferramentas SIG, utilizouse o mapa digital da área urbana do Município de Manaus, gerreferenciado em sistemas de projeção geográfica DATUM SAD 69, e imagens do satélite Quickbird 2008 e aerofotogramétrica de 2010. As comunidades do estudo foram visitadas in loco nos segundo semestre do ano de 2007. Os resultados mostram características semelhantes uma para com as outras devido à falta de ordenamento e planejamento para estruturação e edificação de residências, comércios, ruas, sistemas de abastecimento de água, sistemas de rede coletora de esgoto sanitário e industrial, coleta de lixo. Os lotes das quatro comunidades do estudo não obedecem às diretrizes de recuo e afastamentos dos eixos laterais das ruas, distância entre os lotes vizinhos, área máxima para edificação, área para permeabilização e, por consequência, área das quadras e lotes destinados para diferentes atividades urbanas, comércios e até mesmo industriais, desobedecendo ao Plano Diretor Ambiental e Urbano de Manaus. Conclui-se que as comunidades estudadas, pelo seu posicionamento geográfico e estratégico, apresentam situações ambientais caracterizadas por condicionantes naturais e antrópicos, singulares à realidade do cenário atual do Bairro.
\end{abstract}

Palavras-chave: geoprocessamento, manaus, plano diretor.

\begin{abstract}
With the process of urban expansion spurred by population growth and development of productive and commercial activities, among other factors, have brought many problems to cities and their populations. As a consequence of inadequate planning of land use, this expansion has produced a degraded urban environment, with great influence on the quality of life of the population, the main constraints of this disorderly occupation demographic and socioeconomic determinant. In this sense, we studied the structure of an urban area in the East Zone disorderly occupation of the city of Manaus.
\end{abstract}

Keywords: urban expansion, disorderly occupation, Manaus.

*alans_ferreira@hotmail.com

Recebido: 14/03/2014 Aceito: 14/03/2014 


\section{Introdução}

$\mathrm{D}$ esde a implantação da Zona Franca, em 1967, iniciou-se em Manaus um novo ciclo econômico, com a instalação de um parque industrial de grande porte e a consolidação de um setor terciário baseado na comercialização de produtos importados. Nos últimos trinta anos a Zona Franca foi responsável pela atração de um grande fluxo migratório do interior do Estado, do Nordeste e de diferentes regiões do país, como consequência a população de Manaus cresceu mais de $500 \%$, saltando de 300 mil habitantes, na década de 70, para mais de um milhão e 500 mil na virada do século XXI (Nogueira et al, 2007).No intuito de testar a aplicação do geoprocessamento com a elaboração de um SIG, para auxiliar na reorganização urbana das áreas oriundas de invasão, objetivou-se analisar a estrutura urbana e da área de preservação permanente (APP)de uma área de ocupação desordenada na zona leste da cidade de Manaus, visando subsidiar o planejamento urbano da referida área.

\section{Material e métodos}

\section{1. Área de estudo}

As áreas selecionadas para o estudo foram as comunidades Jorge Teixeira $3^{\underline{a}}$ etapa, Bairro Novo, Arthur Virgílio Filho e João Paulo, integrantes da Unidade de Estrutura Urbana UES (bairro) Jorge Teixeira, conforme Plano Diretor Ambiental Urbano de 2008 da cidade de Manaus. Esta área está localizada na parte da montante da Bacia Hidrográfica do Mindu, Zona Leste de Manaus e perfaz um total de aproximadamente 199 ha. A área de projeto está localizada na periferia da cidade de Manaus, cuja acessibilidade local se faz pela Avenida Autaz Mirim via Bairro São José e a Avenida Grande Circular procedente da Cidade Nova (Figura 1).

Para a análise e execução da pesquisa, para o gerenciamento e aquisição dos dados para manipulação das informações cadastrais e dos atributos espaciais, utilizou-se a padronização dos arquivos shapefile (.shp), os softwares utilizados foram o ArcGis 9.3 e Spring 4.1, ferramentas SIG - Sistemas de Informação Geográfica, utilizadas pela Prefeitura Municipal de Manaus, por meio das Secretarias Municipais de Meio Ambiente e Sustentabilidade - SEMMAS e Secretaria Municipal de Infraestrutura - SEMINF.

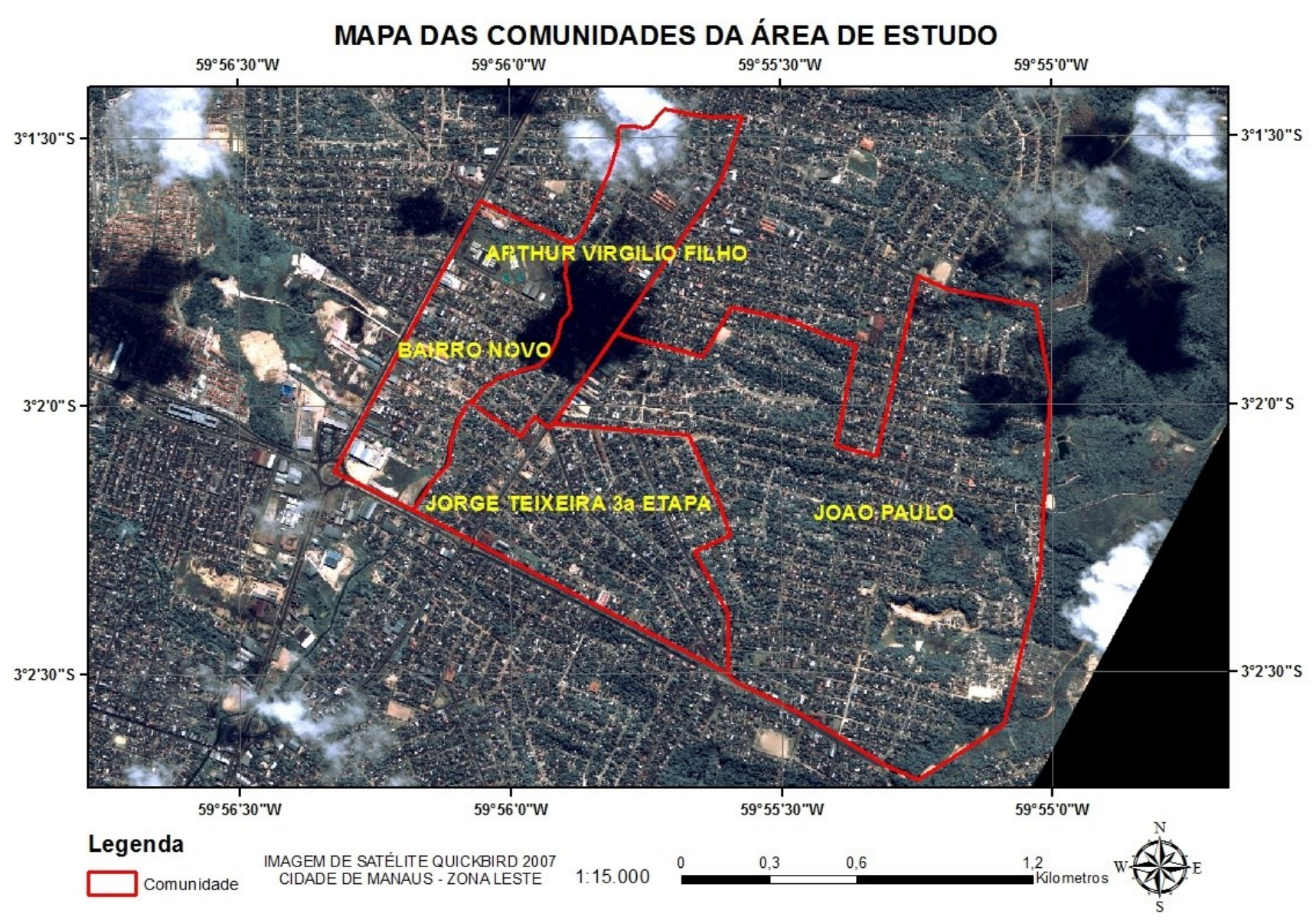

Figura 1. Mapa das comunidades da área de estudo. 


\section{Resultados e discussão}

\subsection{Caracterização dos lotes e edificações}

O processo de intenso crescimento horizontal ocorrido nas áreas estudadas apresentou características dominantes: a abertura de loteamentos populares em áreas distantes do centro da cidade e as invasões, realizadas em glebas urbanas não ocupadas, quanto em terrenos conquistados pela derrubada de áreas florestadas, localizadas quase sempre na periferia da cidade. Estas formas predominantes de ocupação atenderam às demandas das classes mais pobres da população e, principalmente, à pressão dos imigrantes que chegaram à Manaus. As formas de expansão nas comunidades analisadas ocorreram também à ocupação de áreas vazias, localizadas no interstício da malha urbana, através da abertura de loteamentos destinados à classe baixa e média e ao contingente de não trabalhadores e trabalhadores que adquiriram situações instáveis e estáveis de emprego e renda. Os mapas (Figura 2 e 3) mostram a estrutura urbana das áreas estudas com sobreposição de buffer de $3 \mathrm{~m}$ de arruamento e os lotes, indicando a forma ideal das ruas e em conformidade com o Plano Diretor Urbano e Ambiental de Manaus e, também, a natureza da disposição dos lotes na área de estudo.

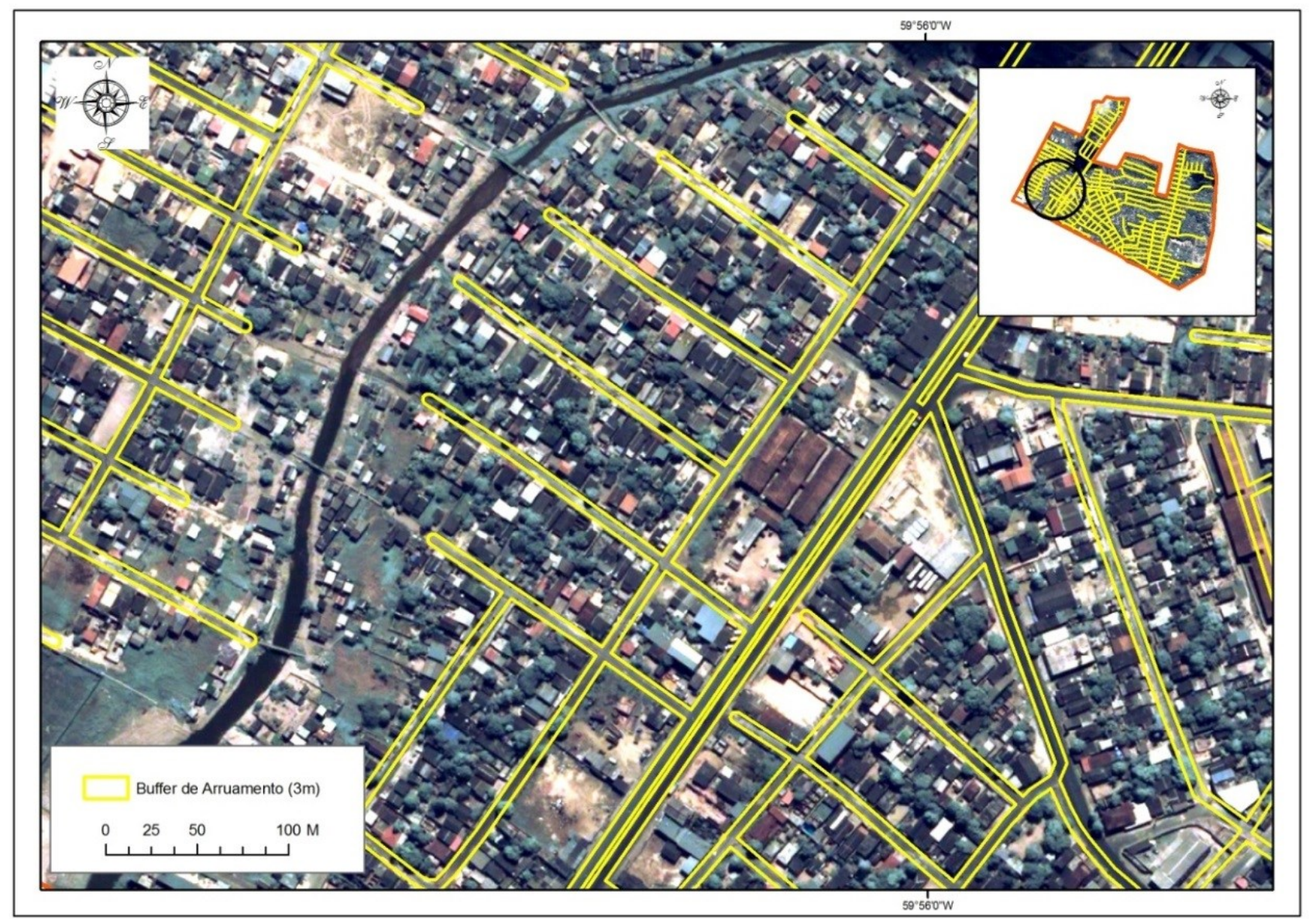

Figura 2. Mapa com o buffer de arruamento da comunidade Bairro Novo. 


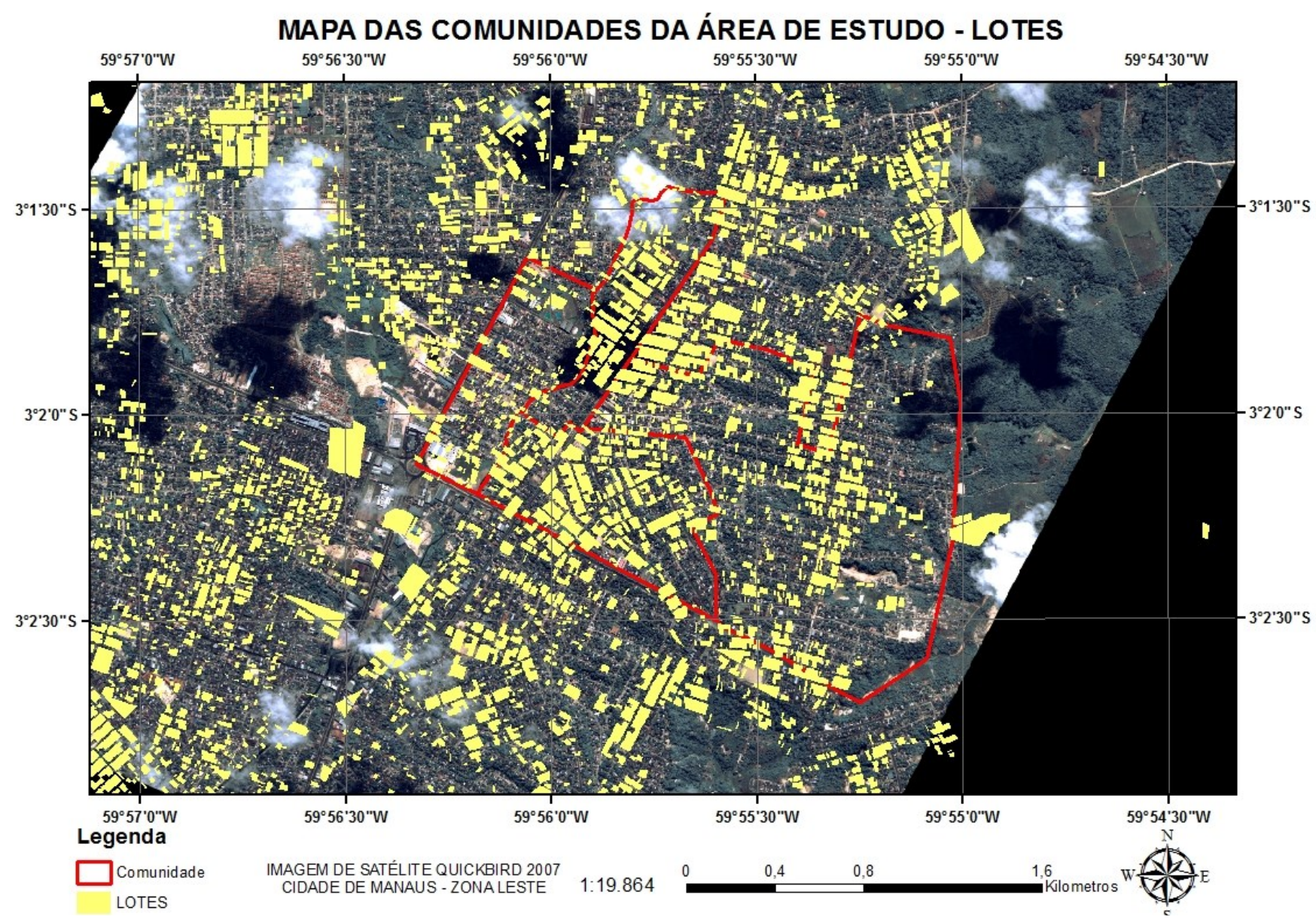

Figura 03. Mapa de situação dos lotes.

\section{Conclusão}

As comunidades estudadas, pelo seu posicionamento geográfico e estratégico, apresentam situações ambientais caracterizadas por condicionantes naturais e antrópicos, singulares à realidade do cenário atual do Bairro. Os fatores antrópicos induziram a proliferação intensa de áreas com instabilidades ambientais (erosão do solo e enchentes). No entanto, os fatores naturais (solo, morfometria) induzem à presença de áreas potenciais antrópicas com aptidões para e expansão urbana, comercial e mista. A avaliação da estrutura urbana realizada com o apoio de geoprocessamento mostrou a realidade da estrutura urbana de uma pequena área da cidade de Manaus.

\section{Referências}

NOGUEIRA, A. C. F.; SANSON, F.; PESSOA, K. A expansão urbana e demográfica da cidade de Manaus e seus impactos ambientais. Anais XIII Simpósio Brasileiro de Sensoriamento Remoto, Florianópolis, Brasil, 21 -26 abril 2007, INPE, p. 5427-5434.

PLANO DIRETOR DA CIDADE DE MANAUS - Atualizado em Abril/2008. Incluído neste documento até a Resolução № 004/2008 do CMDU. Disponível em: www.manaus.am.gov.br/ planodiretordemanaus/. Acesso em: 25/05/2008. 